\title{
A COAGULATION-FLOCCULATION PROCESS COMBINED WITH ADSORPTION USING ACTIVATED CARBON OBTAINED FROM SLUDGE FOR DYE REMOVAL FROM TANNERY WASTEWATER
}

\author{
MAYERLY J. PUCHANA-ROSERO , EDER C. LIMA ${ }^{a}$, BIANCA MELLA ${ }^{b}$, DIMITRIUS DA COSTA \\ EDUARDO POLL ${ }^{b}$, MARILIZ GUTTERRES ${ }^{b}$ \\ a.Institute of Chemistry, Federal University of Rio Grande do Sul (UFRGS), Av. Bento Gonçalves,9500, Porto Alegre-RS, Brazil, 91501-970, \\ ${ }^{b}$. Chemical Engineering Department, Laboratory for Leather and Environmental Studies (LACOURO), Av. Luiz Englert s/n ${ }^{\circ}$ \\ Porto Alegre-RS, Brazil, 90040-040, (51)3308-3954
}

\begin{abstract}
Coagulation-flocculation (CF) process studies on aqueous solutions of Acid Black 210 dye (AB-210), were performed to investigate efficiency at different $\mathrm{pH}$, coagulant and polyelectrolyte doses, and sedimentation times. In the adsorption studies of the dye removal, the initial $\mathrm{pH}$ and isotherms studies were performed using an activated carbon prepared by microwave-assisted pyrolysis of Tannery sludge. This adsorbent material was characterized by isotherms of $\mathrm{N}_{2}$ adsorptiondesorption and density functional theory. Finally, the efficiency of the combined process CF followed by adsorption, was shown using a synthetic effluent identical to that produced in the wet-end process of the leather industry in industrial equipment. Effluent was collected from each treatment bath and analyzed for its physical properties and by ion chromatography.

The best conditions found in CF processes were: $\mathrm{pH} 10.0$, sedimentation time of 60 minutes, coagulant dose of $71 \mathrm{mg} \mathrm{L}^{-1}\left(\mathrm{Al}_{2}\left(\mathrm{SO}_{4}\right)_{3}\right)$ and dose of flocculant (polyelectrolyte FX AS1) of $0.090 \mathrm{mg} \mathrm{L}^{-1}$ In the adsorption processes, the equilibrium data were best fit to the Liu isotherm model, presenting the maximum sorption capacity $\left(\mathrm{Q}_{\max }\right)$ for $\mathrm{AB}-210$ of $974.7 \mathrm{mg} \mathrm{g}^{-1}$ at $303.15 \mathrm{~K}$ at $\mathrm{pH} 2.0$. Using the synthetic effluent, the combined CF followed by adsorption of $\mathrm{AB}-210$ dye demonstrated a removal of $85.2 \%$, indicating that the combined process is efficient for real wastewater treatment.
\end{abstract}

Keywords: adsorption, coagulation-flocculation, dyes, leather industry, wet-end process.

\section{INTRODUCTION}

Tanneries process animal hide/skin through some or all stages and steps of leather production. Tanneries can be classified by the kind of raw material (hide, fell or skin) and the type of the tanning system, which depends on the tanning substance (mineral or organic). Tanneries can be categorized, according to the stages of production, as follows [1]: (a) Complete tanneries, which start from raw hide (green or preserved) and produce finished leather; (b) Beamhouse tanneries, that process raw hide up to the tanning step; (c) Tanneries for leather wet-end and finishing, which start from leather (wet-blue) and produce crust or finished leather.

The wet-end process includes dyeing, which is a key process for the leather industry, because it gives the desired color and appeal to the leather [2]. Dyeing contamination contributes to the elevation of chemical oxygen demand of wastewaters. Even at low dye concentrations these substances change the color of the water significantly, causing aesthetic damage. Water contamination caused by dye-related industries is constantly threatening ecological equilibrium and human health, therefore wastewater treatment improvements are becoming increasingly urgent [3-4].

Coagulation of dye-containing wastewater has been used for many years as its main treatment or pretreatment, due to its low capital cost [5], and coagulants based on hydrolyzing metal salts such as aluminum are widely used. To improve coagulation, the addition of polymers as flocculant aids has been shown to enhance the effectiveness of dye removal by enlarging the size of flocs and consequently causing rapid settling. When inorganic coagulants destabilize the system, polymers improve the rate of orthokinetic flocculation [6].

However, in order to maximize the efficacy of the isolated coagulationflocculation process, in recent years other methods for wastewater treatment have been used in combination, including: nanofiltration [7], ozonation [8], photocatalytic oxidation [9], Fenton and solar Photo- Fenton processes [10], forward osmosis [11] and also adsorption processes [12-15].

Adsorption, is one of the most widely used methods because it is inexpensive, easy to handle and performs impressively in the removal of toxic dyes from industrial wastewater [16]. It has been widely studied for dye removal using different kinds of adsorbents and adsorbates [16-22]. In the leather industry, tannery solid waste has been used as an adsorbent in dye removal [2].

Taking cost and efficiency into account, previous studies have reported the combination of the coagulation-flocculation $(\mathrm{CF})$ and adsorption processes, for the removal of tannic and humic acids [14] and reactive dyes [12-13] of aqueous effluents

Searching for alternative methods of treatment for dye effluents of the leather industry, specifically from the wet-end process, this paper presents research into achieving increased efficiency by using coagulation-flocculation followed by adsorption. This was accomplished using a novel activated carbon prepared by microwave-assisted pyrolysis of an organic precursor obtained from the sludge of a Tannery Wastewater Treatment Plant (ACT) and Commercial Activated Carbon (AC) in an aqueous solution of AB-210, and later applying it in wet-end tannery wastewater under similar experimental conditions as those of industrial processes.

\section{MATERIALS AND METHODS}

2.1 Solutions and reagents

A stock dye solution of $5,000 \mathrm{mg} \mathrm{L}^{-1}$ was prepared with distilled water, which was further diluted in the experiments. The $\mathrm{pH}$ of the solution was adjusted with $0.1 \mathrm{~mol} \mathrm{~L}^{-1} \mathrm{NaOH}$ and/or $0.1 \mathrm{~mol} \mathrm{~L}^{-1} \mathrm{HCl}$ using a Digimed DM-22 pH meter. The dye concentration was measured with a UV/visible spectrophotometer (T80 UV-VIS spectrophotometer, PG Instruments, Leicester, UK). Standard solutions of AB- 210 of between 10.00 and 190.00 $\mathrm{mg} \mathrm{L}^{-1}$ were used for analytical calibration in parallel with deionized water, for the determination of the initial and final dye concentrations. If the absorbance was greater than 2.2 , the necessary dilution was made with a solution of the appropriate $\mathrm{pH}$. The coagulant used was aluminum sulfate $\left(\mathrm{Al}_{2}\left(\mathrm{SO}_{4}\right)_{3}\right)$ and the anionic polyelectrolyte FX AS1 of FAXON Company, (Novo Hamburgo, Brazil, CAS:25987-30-8).

For coagulation-flocculation assays stock solutions of $50.0 \mathrm{mg} \mathrm{L}^{-1}$ of coagulant $\left(\mathrm{Al}_{2}\left(\mathrm{SO}_{4}\right)_{3}\right)$ and $80.0 \mathrm{mg} \mathrm{L}^{-1}$ of polyelectrolyte were prepared.

\subsection{Coagulation and coagulation-flocculation tests}

To verify the effect of $\mathrm{pH}$ on the coagulation/flocculation process, aqueous solutions of $100.0 \mathrm{mg} \mathrm{L}^{-1}$ of $\mathrm{AB}-210$, were prepared at $\mathrm{pH}$ values ranging from 1 to 10 using $0.1 \mathrm{~mol} \mathrm{~L}^{-1} \mathrm{HCl}$ and/or $\mathrm{NaOH}$. Using a Jar Test $218 \mathrm{LDB}$ instrument, $700 \mathrm{~mL}$ of dye solution was treated with a fixed concentration of aluminum sulfate of $143.0 \mathrm{mg} \mathrm{L}^{-1}(2 \mathrm{~mL})$ with agitation at $150 \mathrm{rpm}$ for $5 \mathrm{~min}$. A solution of $80.0 \mathrm{mg} \mathrm{L}^{-1}(1 \mathrm{~mL})$ of polyelectrolyte was added and the agitation was maintained at $40 \mathrm{rpm}$ for $15 \mathrm{~min}$. After stopping the agitation, the final dye concentration was analyzed after 60 minutes of sedimentation time. All experiments using physical-chemical treatments of the aqueous dye solution were carried out in duplicate at room temperature.

For the test of the coagulant dosage, a dye solution of $100 \mathrm{mg} \mathrm{L}^{-1}$ at $\mathrm{pH}$ 
10 was prepared. The experimental conditions for agitation and sedimentation were the same as for the pH tests, only varying the concentration of the coagulant doses between $14 \mathrm{mg} \mathrm{L}^{-1}$ and $214 \mathrm{mg} \mathrm{L}^{-1}$ without the use of polyelectrolyte. The amount of coagulant added to the Jar Test was determined using the mathematical expression (1):<smiles>[R]OS(=O)(=O)c1cc2cc(S(=O)(=O)[O-])c(N=Nc3ccc([N+](=O)[O-])cc3)c(N)c2c(O)c1N=Nc1ccc(S(=O)(=O)Nc2ccc(N=Nc3ccc(N)cc3N)cc2)cc1</smiles>

Figure 1. Molecular structure of the AB-210 dye.

$$
\text { Sulfate Volume }=\frac{A * 0.07}{B} \text { Sulfate Volume }=\frac{A * 0.07}{B}
$$

where $\mathrm{A}$, is the desired $\mathrm{Al}_{2}\left(\mathrm{SO}_{4}\right)_{3}$ concentration in the studied solution in $\mathrm{mg} \mathrm{L}^{-1}, \mathrm{~B}$ is the sulfate concentration in $\mathrm{mg} \mathrm{L}^{-1}$, and 0.07 is a value representing the studied volume of $700 \mathrm{~mL}$, using a settling time of 60 minutes.

The percentage of dye removal was calculated according to the following mathematical expression (Eq. 1):

$$
\% \text { Removal }=100 \cdot \frac{\left(C_{o}-C_{f}\right)}{C_{o}}
$$

$C_{0}$ is the initial concentration of dye $\left(m g \cdot L^{-1}\right)$ and $C_{f}$ is the final dye concentration after the adsorption procedure.

The test of the polyelectrolyte dose was performed under the same experimental conditions, and the coagulant concentration was maintained constant at $71 \mathrm{mg} \mathrm{L}^{-1}$ to evaluate the effect of the polyelectrolyte addition. The volume of stock solution of polyelectrolyte at a concentration of $80.0 \mathrm{mg} \mathrm{L}^{-1}$ added varied from 0.2 to $6 \mathrm{~mL}\left(0.023 \mathrm{mg} \mathrm{L}^{-1}-0.686 \mathrm{mg} \mathrm{L}^{-1}\right)$, using a settling time of 60 minutes.

\subsection{Preparation of activated carbon from tannery sludge (ACT)}

The ACT was prepared by chemical activation of the sludge collected from a tannery wastewater treatment plant using zinc chloride and lime to form a paste (1:1 between the sludge and the inorganic material) and carbonized by microwave heating. The carbonized material was refluxed with $6.0 \mathrm{~mol} \mathrm{~L}^{-1}$ $\mathrm{HCl}$, dried, ground and sieved to obtain the activated carbon [16-18].

The results of the gas-solid isotherms were analyzed in different ranges of pressures, using the BET method on which calculation of specific surface ( $p$ / $\mathrm{p}^{0}$ range determined using the method proposed by Rouquerol et al. [23], and density functional theory $\left(\mathrm{p} / \mathrm{p}^{0}\right.$ range $\left.10^{-7}\right)$, which considered different pore models and the effects of surface roughness and heterogeneity (NLDFT and QSDFT), using the ASQiWin software [24-25].

While the calculation NLDFT has proven to be a reliable method for the characterization of a variety of materials ordered and structured, it has the drawback that it does not consider the geometric and chemical heterogeneity on the walls of the pores, assuming the structure behaves as a flat or even surface. Thus, there is a need for further study considering surface roughness, which is a characteristic in most carbonaceous materials. The QSDFT method was originally developed to take account of this and has been applied to slit-shaped pores, assuming typical models are microporous activated carbons [24-25]. However, the emergence of new materials with pore morphology, for example, predesigned and obtained by synthesis of various precursors, requires the development of new methods that take into account more complex geometric details (slit, cylindrical, spherical and combinations) [24-25].

\subsection{Adsorption Tests}

An aliquot of $20.00 \mathrm{~mL}$ of AB-210 solutions (10.00-1500.0 mg L-1) was added to a $30.0 \mathrm{mg}$ of ACT activated carbon in different $50.0 \mathrm{~mL}$ Falcon conical tubes at different $\mathrm{pH}$ values (1.0-7.0). A temperature-regulated shaker (operating at $200 \mathrm{rpm}$ ) was used to agitate the adsorbent-adsorbate mixtures After agitation at a specified time, the mixtures were centrifuged for $5 \mathrm{~min}$ for separation of the dye solutions from adsorbents $[19,26]$. After the batch adsorption experiment, the unadsorbed dyes were measured using a T90+ PG Instruments spectrophotometer at a maximum wavelength of $615 \mathrm{~nm}$ for $\mathrm{AB}$ 210 dye. The adsorbed quantity of dye per unit mass of activated carbon is given by Eqs. (3)

$$
q=\frac{\left(C_{o}-C_{f}\right)}{m} \cdot V
$$

For the equilibrium studies, the Langmuir, Freundlich, and Liu models were used to analyze equilibrium data. The equations describing these models are shown below [27]

$$
\begin{aligned}
& q_{e}=\frac{Q_{\max } \cdot K_{L} \cdot C_{e}}{1+K_{L} \cdot C_{e}} \\
& q_{e}=K_{F} \cdot C_{e}^{1 / n_{F}} \\
& q_{e}=\frac{Q_{\max } \cdot\left(K_{g} \cdot C_{e}\right)^{n_{L}}}{1+\left(K_{g} \cdot C_{e}\right)^{n_{L}}}
\end{aligned}
$$

Where $\mathrm{q}_{\mathrm{e}}\left(\mathrm{mg} \cdot \mathrm{g}^{-1}\right)$ is the amount of dye removed by ACT at equilibrium; $\mathrm{C}$ ( $\mathrm{mg} \mathrm{L}^{-1}$ ) is the dye concentration at equilibrium; $\mathrm{Q}_{\max }\left(\mathrm{mg} . \mathrm{g}^{-1}\right.$ ) is the maximum adsorption capacity of the $\mathrm{ACT} ; \mathrm{K}_{\mathrm{L}}\left(\mathrm{L} \mathrm{mg}^{-1}\right), \mathrm{K}_{\mathrm{F}}\left[\mathrm{mg} \mathrm{g}^{-1} \cdot\left(\mathrm{mg} \mathrm{L}^{-1}\right)^{-1 / \mathrm{FF}}\right]$ and $\mathrm{K}_{\mathrm{g}}(\mathrm{L}$ $\mathrm{mg}^{-1}$ ) are the respective Langmuir, Freundlich and Liu equilibrium constants, $\mathrm{nF}$ and $\mathrm{nL}$ are the exponents of Freundlich and Liu models, respectively, (nF and $\mathrm{nL}$ are dimensionless) $[28,29]$.

2.5 Statistical evaluation of kinetics and equilibrium models.

Usually for testing a given kinetic and equilibrium model, some statistical functions are tested. The best fit model is the one with the lowes value of Standard Deviation (SD) and the one in which the value of Adjusted Coefficient of Determination $\left(R^{2}\right)$ is closer to unity. Equations $8-11$ depict the expressions of reduced chi-square, $\mathrm{SD}$, Coefficient of Determination $\left(R^{2}\right)$ and adjusted Coefficient of Determination $\left(R_{a d}^{2}\right)$, respectively.

$$
\begin{aligned}
& \text { Reduced Chi-squared }=\sum_{i}^{n} \frac{\left(q_{i, \text { exp }}-q_{i, \text { model }}\right)^{2}}{n_{p}-p} \\
& \mathrm{SD}=\sqrt{\left(\frac{1}{n_{p}-p}\right) \cdot \sum_{i}^{n}\left(q_{i, \exp }-q_{i, \text { odel }}\right)^{2}} \\
& R^{2}=\left[\frac{\sum_{i}^{n p}\left(q_{i, \text { exp }}-\bar{q}_{i, \text { exp }}\right)^{2}-\sum_{i}^{n p}\left(q_{i, \text { exp }}-q_{i, \text { model }}\right)^{2}}{\sum_{i}^{n}\left(q_{i, \text { exp }}-\bar{q}_{i, \exp }\right)^{2}}\right]
\end{aligned}
$$




$$
R_{a d j}^{2}=1-\left(1-R^{2}\right) \cdot\left(\frac{n_{p}-1}{n_{p}-p-1}\right)
$$

where $q_{i}$, isel is each value of $q$ predicted by the fitted model, $q_{i}$ is each value of $q$ measured experimentally, $\bar{q}_{\text {exp }}$ is the average of $q$ experimentally measured, $n_{p}$ is the number of experiments performed and $p$ is the number of parameters of the fitted model.

The reduced chi - squared is the residual sum of squares divided by the degree of freedom (n-p) (Eq. 8). The SD is the square root of reduced chisquared (Eq. 9). Both Equations 8 and 9 are very useful for point to point evaluation of a given kinetic or equilibrium adsorption model, this is because for each experimental point there is a point in the model that corresponds exactly to the point on the curve (model). The lower the reduced chi-squared and the SD, the lower the difference between the values of experimental $q$ $\left(q_{i}\right)$ and model $q\left(q_{\text {inde }}\right)$, therefore, the best fit is expected. However, it should be taken into account that it is not possible to compare the values of reduced chi-squared and SD among several kinetic and equilibrium isotherms that present other different concentrations or other conditions since the values of SD and chi-squared tend to increase as the concentration increases [28]. On the contrary, for the same set of experimental data, the values of reduced chisquared and SD are useful to ascertain the best model since $R^{2}$ and $R_{a d j}^{2}$ are of low sensitivity (their values are limited to unity) [28].

2.6 Wet-end processing wastewater, characterization and treatments

To obtain wastewater with characteristics similar to those of the wastewater generated in the wet-end stage of the tannery industry, the wet-end process was carried out using a pilot-scale tannery drum (Master FLD-8 model) according to the formulation (Table 1), where the input percentage of the chemicals and water were based on the mass of wet-blue leather used $(1.51 \mathrm{~kg})$. Chemicals specialized to the leather industry were used (BASF; TFL; LANXESS).

The steps of the wet-end process were: washing, desacidulation, retanning, preliminary dyeing, fat liquoring and secondary dyeing. In each step the wastewaters generated were collected and refrigerated at $-10^{\circ} \mathrm{C}$ until they could be used in the wastewater treatment assays.

Table 1. Formulation for wet-end processing of wet-blue leather

\begin{tabular}{|c|c|c|c|c|}
\hline Percentage (\%) & Product & $\begin{array}{c}\text { Temperature } \\
\left.\left({ }^{\circ} \mathrm{C}\right) \mathrm{C}\right)\end{array}$ & Time & Remarks \\
\hline 200 & Water & 40 & & \\
\hline 0.20 & Surfactant (Eusapon LDE ${ }^{1}$ ) & & $20^{\prime}$ & Drain \\
\hline 150 & Water & 40 & & \\
\hline 1 & Sodium formate & & & \\
\hline 0.5 & Sodium bicarbonate & & $20^{\prime}$ & \\
\hline 2 & Desacidulation Agent (Sellasol NG²) & & $60^{\prime}$ & pH 5.20-5.50 \\
\hline 100 & Water & 40 & & \\
\hline 5 & Synthetic Tanning (Basyntan DLE³) & & & \\
\hline 2 & Retanning polymer(ReluganRV ${ }^{4}$ ) & & & \\
\hline 2 & Vegetable tannin (Mimosa extract ${ }^{5}$ ) & & $60^{\prime}, 120^{\prime}$ & Drain \\
\hline 100 & Water & 25 & & \\
\hline $2.5 \mathrm{X}$ & Acid Black 2106) & & 60 & Drain \\
\hline 100 & Water & 60 & & \\
\hline 5 & Oil (Lipoderm Licker LA-SLF7) & & & \\
\hline 2 & Synthetic Oil (Coriol L2T48) & & $60^{\prime}$ & \\
\hline 1 & Formic Acid & & $10^{\prime}$ & $\begin{array}{c}\mathrm{pH}=3.5 \\
\text { and Drain }\end{array}$ \\
\hline 200 & Water & 60 & & \\
\hline $1.5 \mathrm{X}$ & Acid Black $210^{9}$ & & $30^{\prime}$ & \\
\hline $\mathrm{X} / 2$ & Formic Acid & & $15^{\prime}$ & Drain \\
\hline
\end{tabular}

\section{$1,3,4,5,7,8$ BASF; ${ }^{2}$ TFL; LANXESS ${ }^{6,9}$}

The generated wastewaters after each stage, were collected and analyzed for $\mathrm{pH}$, conductivity, ionic chromatography and total organic carbon. Finally, they were mixed to obtain a composite wastewater for treatment.

Cation concentrations were determined using an Ionic Chromatography 883 Basic IC Plus Metrolab instrument using a Metrosep C4-150 column. The eluent used was $2.5 \mathrm{mM} \mathrm{HNO}_{3}$ and $1.5 \mathrm{mM}$ dipicolinic acid, with a flow-rate of $0.9 \mathrm{~mL} \cdot \mathrm{min}^{-1}$, a pressure $6.3 \mathrm{MPa}$ at room temperature, and a conductivity of $1196 \mu \mathrm{S} / \mathrm{cm}$. This column allowed the determination of the following cations: lithium, sodium, ammonium, calcium and magnesium. All the analyses were performed using Milli-Q water for washing of the glass materials and for the respective dilutions.

The total organic carbon was determined using a Shimadzu TOC-L, instrument which uses the NPOC (non-purgeable organic carbon) method and the inlet gas was oxygen $\left(\mathrm{O}_{2}\right)$. All the analyses were performed using Milli-Q water for washing of the glass materials and for the respective dilutions.

The optimal conditions obtained for dye removal from aqueous solution (at $303 \mathrm{~K}$ ) were used for the coagulation-flocculation and adsorption treatments of the wet-end composite wastewater, using $30.00 \mathrm{mg}$ of ACT or AC being used for this combined treatment test.

The spectrum from 300 to $800 \mathrm{~nm}$ were recorded for each treatment, and Microcal Origin 2015 software was used to determinate the percentage of dye removal using the calculated integral under the curve for each analyzed treatment process.

\section{RESULTS AND DISCUSSION}

3.1 Coagulation-flocculation process

Fig. 2 shows the dependence of the coagulation-flocculation and 
sedimentation processes on initial $\mathrm{pH}$. Aluminum sulfate at a fixed concentration of $143.0 \mathrm{mg} \mathrm{L}^{-1}$ was added to each vat in the jar test with agitation at $150 \mathrm{rpm}$ for 5 minutes, followed by agitation at $40 \mathrm{rpm}$ for 15 minutes after the addition of the polyelectrolyte at a concentration of $0.114 \mathrm{mg} \mathrm{L}^{-1}$. Samples were collected $15,30,45$ and 60 minutes after agitation ceased in order to evaluate the best settling time. In aqueous solution, $\mathrm{Al}^{3+}$ is a strongly hydrated ion and is found surrounded by six coordinated water molecules in an octahedral configuration. The highly positive charge on the central metal ion causes some polarization of the $\mathrm{O}-\mathrm{H}$ bonds and there is a tendency for protons to dissociate giving one or more hydroxylated species [29]. The chemical reaction (3) represents this process, where the complexes of $\mathrm{Al}^{3+}$ ions in water act as weak acids [6]:

$\mathrm{Al}\left(\mathrm{H}_{2} \mathrm{O}\right)_{6}{ }^{3+} \rightleftharpoons \mathrm{Al}\left(\mathrm{H}_{2} \mathrm{O}\right)_{5}(\mathrm{OH})^{2+}+\mathrm{H}^{+}$

For molecules such as the AB210 dye with a molar weight of 938.02 g. $\mathrm{mol}^{-1}$, this reaction can lead to precipitation of the aluminum-dye complex [30], which was observed in the experiments.

Analyzing the data, 60 minutes settling time resulted in the best dye removal. In the acid $\mathrm{pH}$ range between 1 and 3, only $15.31 \%$ dye removal was achieved. However, above $\mathrm{pH} 4.0$ the dye removal percentage increases quickly reaching $62.80 \%$ at $\mathrm{pH} 4.0$ and was most efficient at basic $\mathrm{pH}$ with $93.2 \%$ removal at $\mathrm{pH} 10.0$. This is likely because the auxochrome group of the dye molecule has a high degree of dissociation and thus the solubility of alum is also high [12].

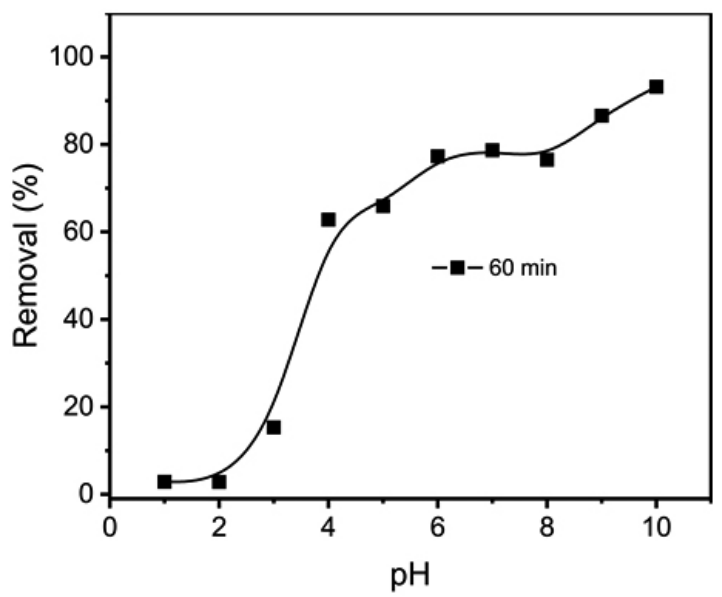

Figure 2. Effect of $\mathrm{pH}$ on the removal of $\mathrm{AB}-210$ dye in the coagulation process $\left(\left(\mathrm{Al}_{2}\left(\mathrm{SO}_{4}\right)_{3}\right)\right.$ doses $\left.=143 \mathrm{mg} . \mathrm{L}^{-1}\right)$

Fig. 3 shows the results obtained by varying the coagulant dosage from 15 to $215 \mathrm{mg} \mathrm{L}^{-1}$. Between 15 and $50 \mathrm{mg} \mathrm{L}^{-1}$ the dye removal is low, however above $57 \mathrm{mg} \mathrm{L}^{-1}$ the dye removal increases quickly reaching $100 \%$ at $71 \mathrm{mg} \mathrm{L}^{-1}$, at least in the case of the chromophore group of the dye, which is the part that is quantified spectrophotometrically. Between 71 and $215 \mathrm{mg} \mathrm{L}^{-1}$ the dye removal remained constant, reaching the equilibrium concentration.

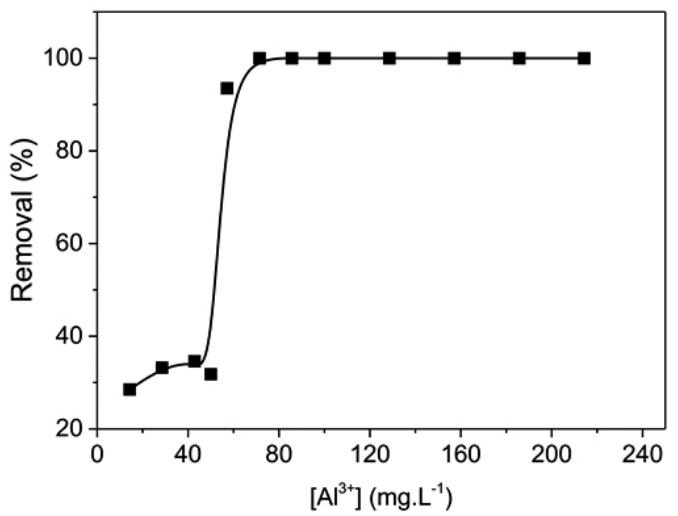

Figure 3. Effect of the $\mathrm{Al}^{3+}$ in the jar test on the removal of $\mathrm{AB}-210$ dye $(\mathrm{pH}=10.00)$.
The polyelectrolyte dosage was varied at the optimal coagulant dose of 71 $\mathrm{mg} \mathrm{L}^{-1}$ and the optimum $\mathrm{pH}$ of 10 (Fig 4). With the polyelectrolyte addition it was observed that the flocs were bigger, facilitating the sedimentation process For this reason, the chosen dose of polyelectrolyte was $0.114 \mathrm{mg} \mathrm{L}^{-1}$ ensuring $100 \%$ of the dye removal at the concentration studied and facilitating the physico-chemical process. The flocculant is a high molecular weight anionic polymer of polyacrylamide, produced with free radicals of acrylamide, which is essentially a common charge of sodium acrylate. The polyelectrolytes act to stabilize colloidal particles of great size, promoting sedimentation. Basically, polyelectrolytes enhance the rate of orthokinetic flocculation when added to a system already stabilized by inorganic coagulants [6].

The increase in flocs only happens when there is sufficient adsorption affinity between the polyelectrolytes and the floc surfaces. The flocs then undergo polyelectrolyte bridging or charge neutralization [31].

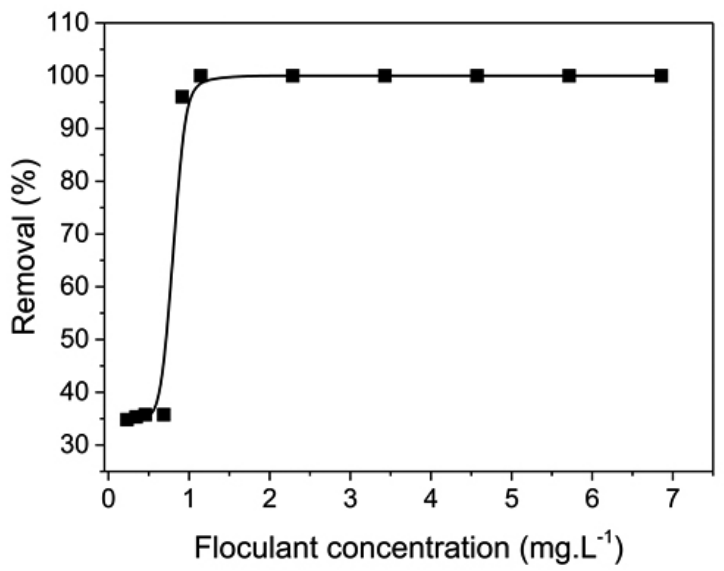

Figure 4. Effect of flocculant concentration (anionic polyelectrolyte) in the jar test for the removal of $\mathrm{AB}-210$ dye $\left(\mathrm{pH}=10.00\right.$ and $\left.71.43 \mathrm{mg} / \mathrm{L} \mathrm{Al}\left(\mathrm{SO}_{4}\right)_{3}\right)$ ). $(A C T)$

3.2. Textural characterization of activated carbon from tannery sludge

The obtained ACT had a surface area BET of $491.0 \mathrm{~m}^{2} \mathrm{~g}^{-1}$. As complementary study, this material was analyzed for the application of the method of Density Functional Theory (DFT), which has led to significant advances in the textural characterization of porous materials and provides information on the size of the pores in the range of micro- and mesopores.

Thus, for this analysis we considered data adsorption-desorption of nitrogen at $77 \mathrm{~K}$ (with a characteristic isotherm of micro-mesoporous activated carbon) (Fig. 5), and applied both a NLDFT model as QSDFT [25] for a wide range geometry (slit, cylindrical and spherical) and combinations (slit/ cylindrical, spherical/cylindrical and spherical/cylindrical/slit) for analysis. Of the different theoretical isotherms adjusted (not shown in this analysis), the errors obtained were correlated and it was found that the best fit was achieved with the QSDFT Carbon- $\mathrm{N}_{2}$ (cylindrical/spherical) system in the field of adsorption (Er 0.17\%) (Fig. 6)

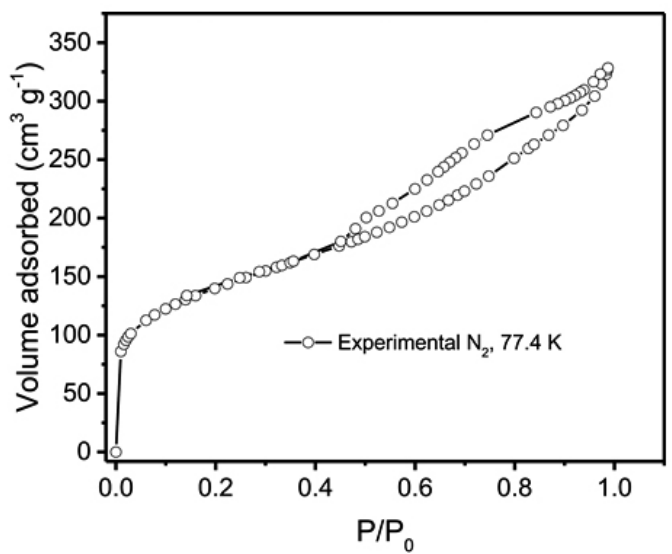

Figure 5. Nitrogen Isotherm adsorption of the activated carbon from tannery sludge (ACT) at $77.4 \mathrm{~K}$ 


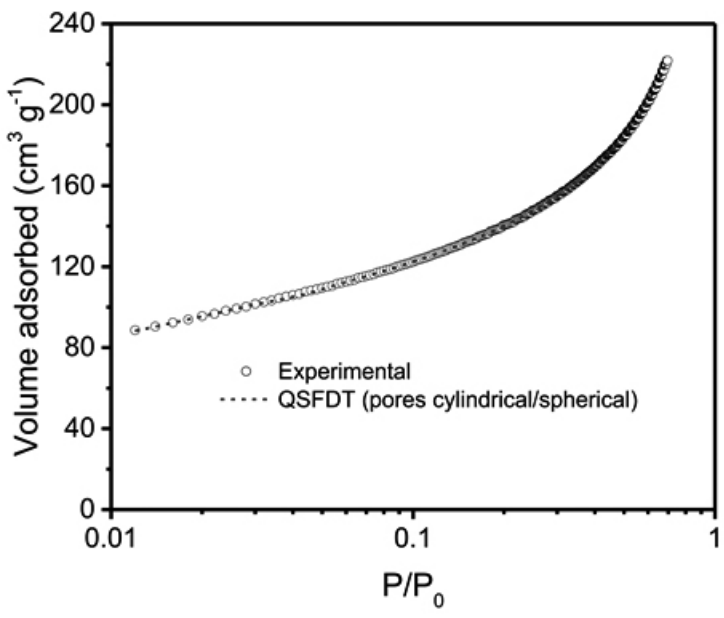

Figure 6. Experimental Nitrogen Isotherm and theoretical adjustment with QSFDT model for adsorption branch (logarithmic scale)

It is noteworthy that the materials have assumed spherical pores present during desorption, an evaporation process altered by the effect called "pore blockage". This assumption is therefore in the analysis with QSDFT carbon- $\mathrm{N}_{2}$ (cylindrical / spherical), only the branch adsorption isotherm $\mathrm{N}_{2}$ was considered to study the size and pore size distribution. Thus, one considers the correct delay in the condensation exists for a spherical pore type [24-25].

Finally, the appropriate model defined, considering the characteristic behavior of the pores of the sample, was used to make the pore size distribution (Fig. 7). The peaks coincide with the pore sizes expected (down is observed in the boundary area micropore and peaks mesopores of different size) and predict the size distribution of micro and mesopores in the whole range of relative pressure (with a volume 0.33 pore $\mathrm{cm}^{3} \mathrm{~g}^{-1}$ and characteristic width of $17 \AA$ ). Additionally, the best fit achieved with the QSDFT model suggests pores of roughness or tortuosity.

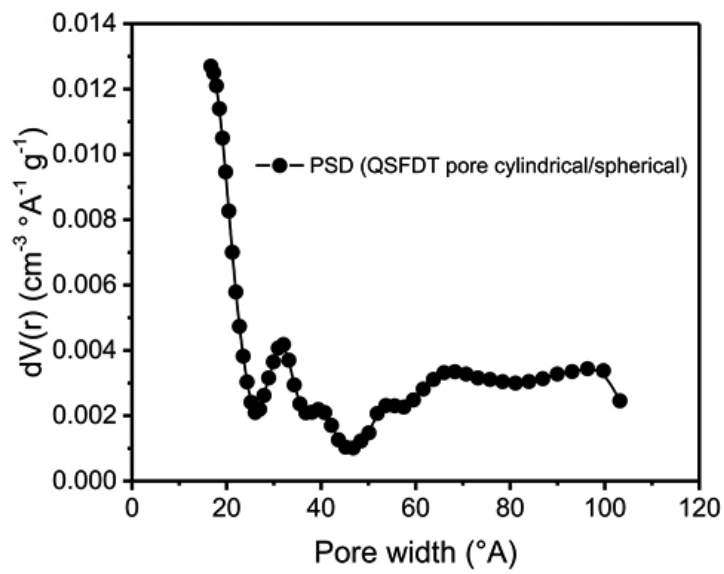

Figure 7. Pore size distribution of activated carbon from tannery sludge (ACT), QSDFT model in the branch of nitrogen adsorption isotherm

3.3 Influence of the $\mathrm{pH}$ on the adsorption process of $A B-210$ using $A C T$

Fig. 8 shows the influence of $\mathrm{pH}$ on the percentage of removal of $\mathrm{AB}-210$ from $\mathrm{ACT}$ activated carbon in aqueous solution. In the $\mathrm{pH}$ interval between $\mathrm{pH} 2.0$ and 6.0, the influence of $\mathrm{pH}$ on the adsorption percentage was not significant.

Considering the experimental evidence that at low $\mathrm{pH}$ such as $\mathrm{pH} 2.00$ 3.00 the activated carbons and the dye solutions are stable, and reports by other authors [19, 32-33], the adsorption of the AB-210 onto the activated carbon seems not be by electrostatic attraction, as the initial $\mathrm{pH}$ of the $\mathrm{AB}-210$ leather dye solutions has practically no effect on the adsorption capacity [32].

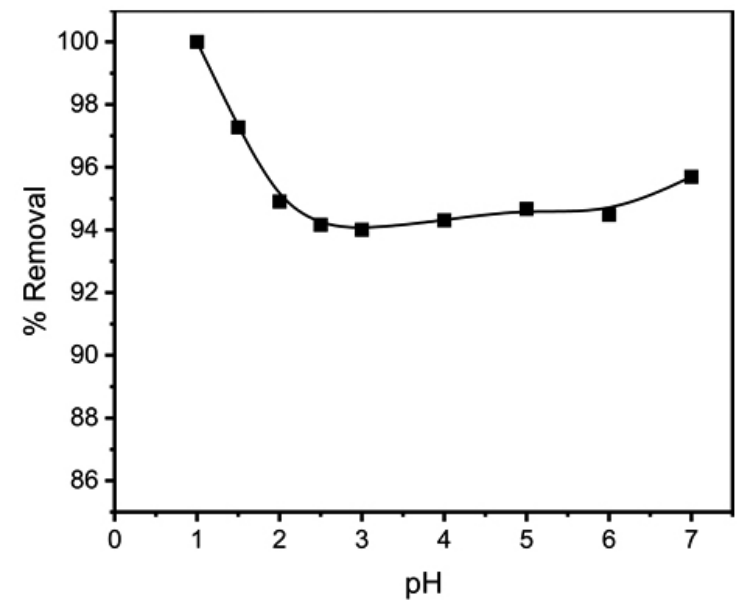

Figure 8. Effect of $\mathrm{pH}$ on the adsorption of $\mathrm{AB}-210$ dye aqueous solution using the activated carbon from tannery sludge (ACT).

\subsection{Equilibrium studies}

Fig. 9 shows the equilibrium study at $303 \mathrm{~K}$ performed to determine the maximum removal of the AB-210 dye using ACT. Table 2 shows the parameters adjusted from the equilibrium experiment on the adsorption of AB210 using the Langmuir, Freundlich and Liu isotherm models. The use of $\mathrm{R}_{\text {adj }}{ }^{2}$ and SD for the analysis of the goodness of fit between the experimental data in aqueous solution and various non-linear adsorption models has been reported in the literature for the comparison of models of 2 and 3 parameters [28,34-36]. Based on $\mathrm{R}^{2}$ as well as the $\mathrm{SD}$, the best isotherm model was the Liu, that presented an SD value of $22.68 \mathrm{mg} \mathrm{g}^{-1}$, which is lower when compared with the $\mathrm{SD}$ of Langmuir (38.60 $\left.\mathrm{mg} \mathrm{g}^{-1}\right)$, and Freundlich $\left(29.04 \mathrm{mg} \mathrm{g}^{-1}\right)$. It could seem, to some readers that the Langmuir and Freundlich isotherm model was better fitted because at the higher $\mathrm{q}_{\mathrm{e}}$ values obtained experimentally gets closer to the $\mathrm{Q}_{\max }$ (theoretical) values of Langmuir isotherm, and also considering that $\mathrm{R}^{2}{ }_{\text {adj }}$ obtained were 0.9583 and 0.9764 for Langmuir and Freundlich model, respectively. However, we reinforce that it is not correct to calculate the $\mathrm{Q}_{\max }$ value based on the supposed plateau of the isotherm. Although several users of adsorption do it, this procedure is not correct. We do reinforce that $\mathrm{q}_{\mathrm{e}}$ (experimental values) could not be directly compared with any $\mathrm{Q}_{\max }$ values, because this is a theoretical parameter that is obtained from an isotherm model [28]. If someone already thinks that the plateau usually obtained in the experimental isotherms is the maximum saturation, this is just the $\mathrm{q}_{\mathrm{e}}$ values obtained for higher concentrations of the adsorbate. The user should be born in mind that any experimental point of the isotherm (even at low adsorbate concentration), the system has attained the equilibrium. Therefore saturation of an adsorbent is quite different of a system attaining a equilibrium.

The maximum adsorption capacity according to the chosen model of Liu, was $974.7 \mathrm{mg} \mathrm{g}^{-1}$ at $303 \mathrm{~K}$. It should be noted that the value of $\mathrm{Q}_{\max }$ is a calculated value that is different from $\mathrm{q}$ values that were experimentally measured. $\mathrm{Q}_{\max }$ is the maximum sorption capacity estimated by a given model. Observing the Liu isotherm at the equilibrium concentration of about 900 $\mathrm{mg} \mathrm{L}^{-1}$ the complete saturation of the adsorbent was not attained yet, and this saturation would occur at higher values. However, considering that the initial $\mathrm{AB}-210$ concentration $\left(\mathrm{C}_{\mathrm{o}}\right)$ is much higher than the equilibrium concentration (C) left at the solution after the adsorption, it is not feasible to increase the concentration of the adsorbate even more, until saturation of the adsorbent occurs.

The fact that the Liu model was the best fit indicates that, due to the heterogeneity of the surface, this is a useful approach to study the behavior of the AB-210 on the surface in the range of concentrations worked. Since the Freundlich model is only appropriate to describe the low concentration region, it is not valid at higher concentrations, where the interactions of the dye molecules in the solution are likely to have a more important role, thus reducing the affinity of the dye towards the surface [37]. The Liu model is similar to the Freundlich isotherm at low concentrations of adsorbate, while at high concentrations it predicts an adsorption monolayer characteristic of the Langmuir isotherm [38]. 


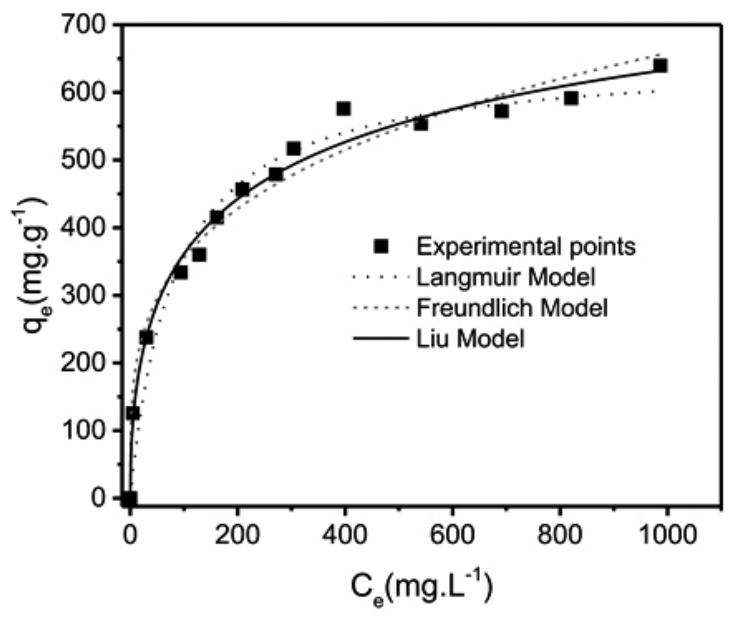

Figure 9. Adsorption isotherm at $303 \mathrm{~K}$ of AB-210 aqueous solution on ACT the activated carbon from tannery sludge (ACT)

Table 2. Parameters adjusted from the equilibrium experiments on the adsorption of AB-210 using the Langmuir, Freundlich and Liu models (303 K)

\begin{tabular}{|c|c|c|c|c|c|}
\hline Langmuir & & Freundlich & & Liu & \\
\hline $\mathrm{Q}_{\text {max }}\left(\mathrm{mg} \cdot \mathrm{g}^{-1}\right)$ & 651.8 & $\mathrm{~K}_{\mathrm{F}}\left(\mathrm{mg}^{-\mathrm{g}^{-1}}\left(\mathrm{mg} \mathrm{L}^{-1}\right)^{-1 / \mathrm{FF}}\right)$ & 103.9 & $\mathrm{Q}_{\max }\left(\mathrm{mg} \cdot \mathrm{g}^{-1}\right)$ & 974.7 \\
\hline $\mathrm{K}_{\mathrm{L}}\left(\mathrm{L} \cdot \mathrm{mg}^{-1}\right)$ & 0.01222 & $\mathrm{n}_{\mathrm{F}}$ & 3.742 & $\mathrm{~K}_{\mathrm{g}}\left(\mathrm{L}_{\mathrm{mg}} \mathrm{m}^{-1}\right)$ & 0.003458 \\
\hline & & & & $\mathrm{n}_{\mathrm{L}}$ & 0.4990 \\
\hline Reduced $\chi 2$ & 1489.6157 & Reduced $\chi 2$ & 843.4991 & Reduced $\chi 2$ & 471.6445 \\
\hline $\mathrm{R}^{2}{ }_{\text {adj }}$ & 0.9583 & $\mathrm{R}_{\text {adj }}^{2}$ & 0.9764 & $\mathrm{R}^{2}{ }_{\text {adj }}$ & 0.9856 \\
\hline $\mathrm{SD}\left(\mathrm{mg} \cdot \mathrm{g}^{-1}\right)$ & 38.60 & $\mathrm{SD}\left(\mathrm{mg} \cdot \mathrm{g}^{-1}\right)$ & 29.04 & $\mathrm{SD}\left(\mathrm{mg} \cdot \mathrm{g}^{-1}\right)$ & 22.68 \\
\hline
\end{tabular}

3.5 Wastewater from the leather wet-end process

Proportional volumes of the drained wastewater discharged from each step of the leather wet-end process performed in a pilot-scale drum were mixed to compose a test effluent Fig. 10 shows the leather obtained and the drum used for the dyeing test and the wastewater collection. Table $\mathbf{3}$ shows the results of the analysis of each wastewater.
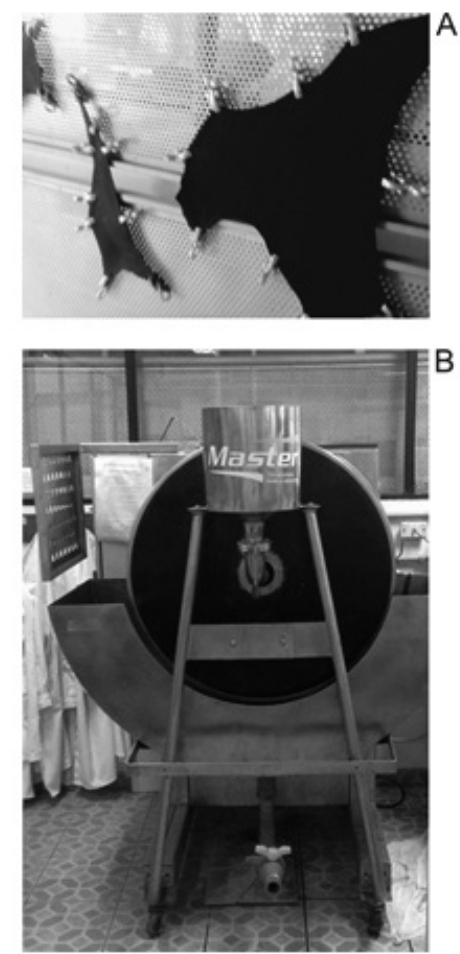

Figure 10. Experimental dyed leather (a) and pilot-scale drum (b) 
Table 3. Characterization of wastewaters of the wet-end process

\begin{tabular}{|c|c|c|c|}
\hline Stream of wastewater & $\mathbf{p H}$ & $\begin{array}{c}\text { Conductivity } \\
\left(\mu \mathrm{S} . \mathrm{cm}^{-1}\right)\end{array}$ & $\begin{array}{c}\text { TOC } \\
\left(\mathrm{mg.L}^{-1}\right)\end{array}$ \\
\hline Initial Washing & 3.88 & 1094.7 & 615.5 \\
\hline Desacidulation & 7.69 & 8.285 & 3401 \\
\hline Tanning & 5.28 & 5.969 & 1823.5 \\
\hline Dyeing I & 7.07 & 7.887 & 2522 \\
\hline Fat liquoring & 3.52 & 5.413 & 4833 \\
\hline Dyeing II & 3.50 & 4.967 & 2137.7 \\
\hline
\end{tabular}

The final concentration of dye in the mixture of all wastewaters collected was $453 \mathrm{mg} \mathrm{L}^{-1}$. Seeing as the precipitate obtained in the coagulation is a complex chemical containing coagulant and dye in aqueous solution, interference of the other chemical products added to the obtained effluent modify the complex formation equilibrium.

The coagulation-flocculation process is caused by the entrapment/ enmeshment of the dye colloid into the gelatinous aluminum flocs, aggregated products of the hydrolysis of aluminum (III) ions, which are then removed by what is known as "sweep coagulation" [36].

However, this sweep coagulation is directly affected by interferents, because other cations like sodium, potassium, and formate compete for complexation with the chromophore group of the dye.

The composed effluent was adjusted to $\mathrm{pH} 10$ with $\mathrm{NaOH}$, and the coagulant volume was varied from 1071 to $7142.9 \mathrm{mg} \mathrm{L}^{-1}$ Considering the present interferents, and the ability of the polyelectrolyte to improve the coagulation process by forming large and heavy flocs, the volume of polyelectrolyte to add to the simulated effluent $(5.27 \mathrm{~mL}$ polyelectrolyte $)$ was calculated according to previous studies with aqueous solutions. With this amount of polyelectrolyte and $4285 \mathrm{mg} \mathrm{L}^{-1}$ of coagulant, a clear precipitation was obtained in this effluent.

Ion chromatography was used to analyze the main cations in the wastewater (Table 4). These analyses were performed in duplicate and the reported values are the averages between them. In the initial effluent without $\mathrm{pH}$ adjustment the concentrations of sodium, ammonium, potassium and calcium were: 1736.170 $\mathrm{mg} \mathrm{L}^{-1}, 145.55 \mathrm{mg} \mathrm{L}^{-1}, 23.442 \mathrm{mg} \mathrm{L}^{-1}$ and $107.111 \mathrm{mg} \mathrm{L}^{-1}$ respectively, deriving from the reagents of the desacidulation step and the composition of the wet blue leather.

Table 4. Chemical analyses of the composite wastewater from wet-end process before and after the treatments.

\begin{tabular}{|c|c|c|c|c|c|}
\hline Composite wastewater & $\begin{array}{c}\text { TOC } \\
\left.(\mathbf{m g ~ L})^{-1}\right)\end{array}$ & $\mathbf{N a}^{+}$ & $\mathrm{NH}_{4}^{+}$ & $\mathbf{K}^{+}$ & $\mathrm{Ca}^{+2}$ \\
\hline Initial & 2024 & 1736.13 & 145.55 & 23.44 & 107.1 \\
\hline Initial adjusted at $\mathrm{pH}=10.00$ & 1567.7 & 1932.17 & 100.02 & ND & ND \\
\hline After coagulation-flocculation treatment & 781.65 & 1454.88 & 80.52 & ND & ND \\
\hline $\begin{array}{l}\text { After coagulation-flocculation and adsorption treatment with } \\
\qquad \mathrm{AC} \text { (Commercial activated carbon) }\end{array}$ & 638.6 & 1345.42 & 73.397 & ND & ND \\
\hline $\begin{array}{l}\text { After coagulation-flocculation and adsorption treatment with } \\
\text { ACT (Activated carbon tannery sludge) }\end{array}$ & 703.85 & 1502.84 & 83.236 & ND & ND \\
\hline
\end{tabular}

The initial effluent shows an increase of the sodium ions amount compared with the composite wastewater, for the basic adjustment from $1736.13 \mathrm{mg} \mathrm{L}^{-1}$ to $1932.17 \mathrm{mg} \mathrm{L}^{-1}$. Ammonium was reduced to $100.02 \mathrm{mg} \mathrm{L}^{-1}$, possibly by ionic competence.

The effluent treated with the coagulation process showed a decrease from the initial cation concentrations of $24.70 \%$ for sodium and $19.49 \%$ for ammonium. The calcium and potassium precipitate completely with the addition of the coagulant, showing the high efficiency of this process.

However, the adsorption process performed at $\mathrm{pH}=3.00$ with $\mathrm{AC}$ evidenced an excellent polishing treatment, showing an adsorption of $7.52 \%$ of sodium ions, and for the ammonium ions the removal was $8.84 \%$ with the $\mathrm{AC}$, compared to the treated wastewater with coagulation. On the other hand, with the ACT a slight increase in these ions was observed, possibly due to the trace composition of the sludge precursor that was maintained despite the leaching on the activated carbon.

From the TOC analysis, it was seen that through the coagulation process, the content of total organic carbon decreased to $50.1 \%$ of the initial content, and after the adsorption process with ACT an additional 5\% reduction in TOC was seen. With AC an additional $9.16 \%$ reduction in TOC was achieved.

The area under the absorption bands between 300 and $800 \mathrm{~nm}$ obtained by the Microcal Origin 9.0 software was used to evaluate the percentage of dye removal from the initial effluent and the treated effluent by the physicochemical process and subsequently also with the adsorption process. The dye removal through the coagulation process was $78.22 \%$. From the initial concentration of the wastewater studies of $453 \mathrm{mg} \mathrm{L}^{-1}$ a residual concentration of $98.66 \mathrm{mg} \mathrm{L}^{-1}$ was obtained. Given the maximum adsorption capacity at the working temperature for the Liu model was $974.7 \mathrm{mg} \mathrm{g}^{-1}$, the ACT could achieve additional dye removal, which was observed experimentally, obtaining a dye removal of $85.2 \%$ when the ACT was used for the adsorption and $88.64 \%$ with the AC.
Fig. 11 shows the absorbance spectra after the different treatments in these studies. They indicate that the combination of treatments provides an excellent alternative that can substantially improve the process. Aluminum sulfate as coagulant, anionic polyelectrolyte as flocculant and the activated carbon (ACT) used are excellent agents for the treatment of leather dye contaminated effluents.

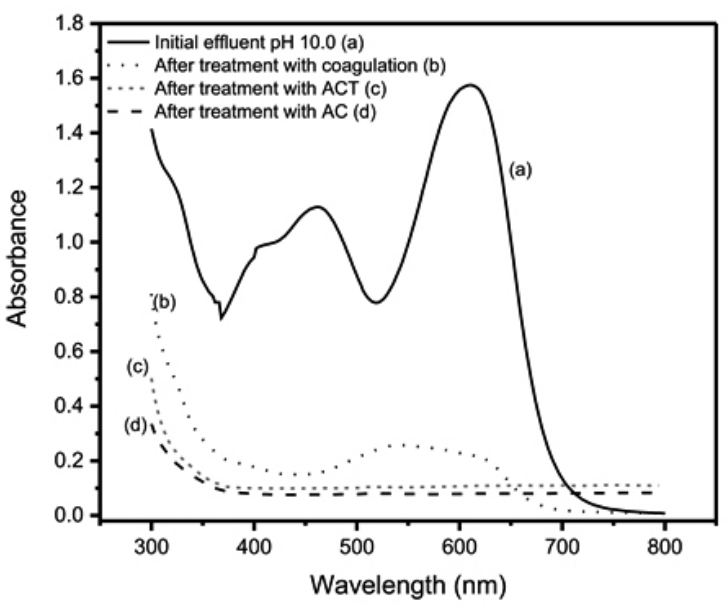

Figure 11. Absorption spectra of the initial effluent of leather wet-end process and after the treatments tested. 


\section{CONCLUSIONS}

The combination of coagulation-flocculation with adsorption processes showed effective results in the removal of the tannery dye Black Acid 210 from aqueous solution and wet-end tannery wastewater.

The ACT was achieved with QSDFT Carbon- $\mathrm{N}_{2}$ (cylindrical / spherical) system in the field of adsorption and presented roughness and tortuosity in its wall pores.

In wet-end tannery wastewater the combination of coagulation-flocculation and adsorption with ACT achieved $85.2 \%$ removal of the dye compared with AC that showed $88.64 \%$. In addition, using the ACT, $68.44 \%, 13.44 \%$, and $42.81 \%$ reductions were achieved for TOC, total sodium, and ammonium. Potassium and calcium were not identified from the solution after the $\mathrm{NaOH}$ addition for $\mathrm{pH}$ adjustment. For the combination process using $\mathrm{AC}$, the results obtained were: $65.22 \%$ TOC removal, $22.5 \%$ total sodium removal, and $49.57 \%$ removal of ammonium.

\section{ACKNOWLEDGEMENTS}

The authors are grateful for funding from the Coordination of Improvement of Higher Education Personnel (CAPES, Brazil) under the program PEC-PG they are grateful to the National Council for Scientific and Technological Development $(\mathrm{CNPq}$, Brazil) and to the Financier of Studies and Projects (FINEP, Brazil) - public call MCTI/FINEP CT-HIDRO 01/2013. The authors thank the Business and Leather Unit of the LANXESS Company for the dye provided.

\section{REFERENCES}

1. M. Gutterres, B. Mella, B. Chromium in Tannery Wastewater. Heavy Metals in Water: Presence, Removal and Safety. 1st ed. Cambridge: Royal Society of Chemistry, 2014; pp. 314-338.

2. J. Piccin, C.S.Gomes, L.A Feris, M. Gutterres. Chem. Eng. J. 183, 30 (2012).

3. Y.F., Feng, H. Zhou, G.H. Liu, J. Qiao, J.H. Wang, H.Y. Lu, L.Z. Yang, Y.H. Wu. Bioresour. Technol. 125, 138, (2012).

4. X.Y. He, K.B. Male, P.N. Nesterenko, D. Brabazon, B. Paull, J.B.T Luong. ACS Appl. Mater. Interfaces 5, 8796(2013).

5. B.H. Tan, T.T. Teng, A.K.M. Omar. Water Res. 34, 597 (2000)

6. J. Bratby, Coagulation and Flocculation in Water and Wastewater Treatment. Second ed., IWA Publishing, 2006.

7. C. Liang, S. Sun, F. Li, Y. Ong, T. Chung. J. Membrane Sci., 469, 306 (2014).

8. M. Rasool, B. Tavakoli, N. Chaibakhsh, A. Pendashteh, A. Ecol. Eng. 90, 431 (2016).

9. I. Michael, A. Panagi, L.A. Loannou, Z. Frontistis, D. Fatta-Kassinos. Water Res. 60, 28 (2014).

10. C. Amor, E. Torres-Socías, J. Peres, M. Maldonado, I. Oller, S. Malato, M. Lucas. J. Hazard. Mater. 286, 261 (2015).

11. G. Han, C. Liang, T. Chung, M. Weber, C. Staudt, C. Maletzko, C. Water Res. 91, 361 (2016).

12. S. Papic, N. Koprivanac, A.L. Bozic, A. Metes. Dyes pigm. 62 (3), 291(2004)

13. F. Furlan, L. Melo da Silva, A. Morgado, A. Ulson de Souza. Resour. Conserv. Recy, 54, 283 (2010)

14. C. Jung, N. Phal, J. Oh, K. Hoon, M. Jang, Y. Yoon. J. Hazard. Mater 300, $808(2015)$

15. V. Oloibiri, I. Ufomba, M. Chys, W. Audenaert, K. Demeestere, S. Van Hulle. Waste Manage. 43, 335 (2015)

16. C. Saucier, M.A. Adebayo, E.C. Lima, R. Cataluna, P.S. Thue, L.D.T. Prola, M.J. Puchana-Rosero, F.M. Machado, F.A. Pavan, G.L. Dotto, J. Hazard. Mater. 289, 18 (2015)

17. M.J. Puchana-Rosero, M.A. Adebayo, E.C. Lima, F.M. Machado, P.S Thue, J.C.P. Vaghetti, C.S. Umpierres, M. Gutterres, Colloid Surf. A, 504, 105 (2016).

18. M. C. Ribas, M. A. Adebayo, L. D.T. Prola, E. C. Lima, R. Cataluña, L. A. Feris, M.J. Puchana-Rosero, F. M. Machado, F. A. Pavan, T. Calvete, Chem. Eng. J. 248, 315 (2014).

19. M.A. Adebayo, L.D.T Prola, E.C. Lima, M.J. Puchana-Rosero, R. Cataluña, C. Saucier, C.S. Umpierres, J.C.P. Vaghetti, L.G. da Silva, R. Ruggiero, J. Hazard. Mater. 268, 43 (2014)

20. L.D.T. Prola, E. Acayanka, E.C. Lima, C.S. Umpierres, J.C.P. Vaghetti, W.O. Santos, S. Laminsi, P.T. Njifon, Ind. Crop. Prod., 46, 328 (2013).
21. N.F. Cardoso, E.C. Lima, B. Royer, M.V. Bach, G.L. Dotto, L.A.A. Pinto, T. Calvete, J. Hazard. Mater. 241-242, 146 (2012).

22. L.D. T. Prola, F.M. Machado, C.P. Bergmann, F.E. de Souza, C.R. Gally, E.C. Lima,_M.A. Adebayo, S.L.P. Dias, T. Calvete, J. Environ. Manage. 130, 166 (2013).

23. J. Rouquerol, P. Llewellyn, F. Rouquerol. Stud. Surf. Sci. Catal. 160, 49 (2007)

24. M. Thommes, K. Kaneko, A. Neimark, J. Olivier, F. Rodríguez-Reinoso, J. Rouquerol, K. Sing. Pure Appl. Chem. DOI 10.1515/pac-2014 (2015)

25. G. Gor, M. Thommes, K. Cychosz, A. Neimark. Carbon, 50, 1583 (2012)

26. J. Landers, G. Yu, A. Neimark. Colloids and Surfaces A: Physicochem. Eng. Aspects. 437, 3 (2013)

27. W.S. Alencar, E.C. Lima, B. Royer, B.D. dos Santos, T. Calvete, E.A. da Silva, C.N. Alves. Sep. Sci. Technol. 47,513 (2012)

28. E.C. Lima, M.A. Adebayo, F.M. Machado. Kinetic and equilibrium models of adsorption. In: Bergmann CP, Machado FM, editors Carbon nanomaterials as adsorbents for environmental and biological applications. Springer; 2015, pp.33-69.

29. C. Saucier, M.A. Adebayo, E.C. Lima, L.D.T. Prola, P.S. Thue, C.S Umpierres, M.J. Puchana-Rosero, F.M. Machado. Clean: Air, Soil, Water, 43, 1389 (2015).

30. A. Zahrim, C. Tizaoui, N.J. Hilal. J. Hazard. Mater., 182, 624 (2010)

31. J.M. Duan, J. Gregory. Adv. Colloid Interface Sci. 100,475 (2003)

32. M.B Silveira, F.A. Pavan, N.F. Gelos, E.C. Lima, S.L.P. Dias, Clean: Air Soil, Water, 42, 939 (2014)

33. T. Calvete, E.C. Lima, N.F. Cardoso, S.L.P. Dias, E.S. Ribeiro. Clean Air, Soil, Water, 38, $521(2010)$

34. D. dos Santos, M.A. Adebayo, F. Pinheiro, L.D.T. Prola, R. Cataluña E.C. Lima, C. Saucier, C. Gally, F. Machado. Korean J. Chem. Eng. 31, $1470(2014)$

35. A. Bazzo, M.A. Adebayo, S.L.P. Dias, E.C. Lima, J.C.P. Vaghetti, E.R. de Oliveira, A.J.B. Leite, F.A. Pavan, Avocado seed powder: characterization and its application for crystal violet dye removal from aqueous solutions, Desalination and Water Treatment, 57, 15873 (2016)

36. M. Shirmardi, N. Alavi, E.C. Lima, A. Takdastan, A.H. Mahvi, A.A. Babaei, Removal of atrazine as an organic micro-pollutant from aqueous solutions: a comparative study, Process Safety and Environmental Protection, 103, 23 (2016).

37. P.A.M. Mourao, P.J.M. Carrot, M.M.L. Ribeiro Carrot. Carbon. 44, 2422 (2006).

38. P.D. Húmpola, H.S. Odetti, A.E. Fertitta, J.L. Vicente. J. Chil. Chem. Soc., 58, 1, 1541 (2013).

39. S. Gaydardzhier, J. Karthikeyan, P. Ay. Environ. Technol. 27 (2) ,193199. 